\title{
ESTUDOS CULTURAIS E FORMAÇÃO PROFISSIONAL EM LAZER Das Identidades e Concepções de Sujeitos
}

\author{
Samuel Santos \\ Universidade do Estado de Minas Gerais, Brasil
}

\begin{abstract}
Resumo: Atualmente, o campo do lazer necessita de novos estudos sobre as concepções de sujeito, sobretudo pela multiplicidade de projetos e propostas de formação nesse setor. O estudo em questão discute identidades culturais e concepções de sujeito, ambas embasadas em Stuart Hall. Com isso, procuro apontamentos dos Estudos Culturais para a formação profissional em lazer. Na metodologia da pesquisa são articulados os referenciais bibliográficos de cultura, currículo e lazer. Assim, pesquisas de currículos para formação profissional em lazer, identidades culturais e atuações em distintos contextos com múltiplos sujeitos são novos mapas de estudo para a área. Logo, precisamos pensar a mobilização de saberes e as transformações nas experiências cotidianas das políticas educacionais, esportivas e culturais com lazer.
\end{abstract}

Palavras-chave: concepções de sujeito; currículo; formação profissional; identidades culturais; lazer.

\section{Introdução}

Essa pesquisa, além de reflexo da formação no curso de mestrado1interdisciplinar, é também produto da participação no Laboratório de Pesquisa sobre Formação e Atuação Profissional em Lazer (ORICOLÉ)². A mesma compreende uma produção científica na perspectiva dos Estudos Culturais.

Como resultado da formação profissional e acadêmica, o estudo desenvolveu-se num processo coletivo e com aproximações interculturais ${ }^{3}$. O mesmo indica a importância do intercâmbio na pesquisa científica e a relevância da troca de experiências entre países, contextos e sujeitos interessados nas ciências humanas e sociais. Ademais, apresenta a necessidade de nexos dos pesquisadores e estudantes interessados na construção de saberes profissionais, acadêmicos e culturais.

\footnotetext{
${ }^{1}$ Programa de Pós-Graduação Interdisciplinar em Estudos do Lazer da Universidade Federal de Minas Gerais (UFMG), Brasil. Endereço eletrônico https://www.ufmg.br/mestradoemlazer/index.php

${ }^{2}$ O Laboratório de Pesquisa sobre Formação e Atuação Profissional em Lazer (ORICOLÉ) está localizado na Escola de Educação Física, Fisioterapia e Terapia Ocupacional (EEFFTO) da (UFMG), na cidade de Belo Horizonte. O grupo de pesquisa Oricolé surgiu junto com a proposta do Mestrado em lazer da (UFMG) e sua agenda de estudos contempla a discussão dos autores dos Estudos Culturais Britânicos e Latinoamericanos. Maiores detalhes podem ser acessados no endereço eletrônico: http://oricole.wordpress.com/ ${ }^{3}$ Uma versão preliminar deste trabalho foi apresentada como comunicação oral no III Congresso Internacional em Estudos Culturais - "Ócio, Lazer e Tempo Livre nas Culturas Contemporâneas”, Aveiro, Portugal, em 2013.
} 
Tenho observado uma ampliação de pesquisas sobre os Estudos Culturais no âmbito da formação profissional em lazer e, com isso, um aumento de abordagens teóricas metodológicas para qualificação desse campo.

A cada semestre, mestrandos e doutorandos da Pós-Graduação tornam-se responsáveis por estudar, sistematizar e relacionar os principais autores dos Estudos Culturais com a formação e atuação em práticas de lazer. As perspectivas teóricas são diversificadas, desde Henry Giroux (1987), Michel Foucault (2004), Stuart Hall (1997, 1998, 2000, 2006), Raymond Williams (1992), Edward Palmer Thompson (1998), Gilles Deleuze (1992) e Richard Hoggart (1973), até as teorias Queer (Louro, 2004) e o multiculturalismo (Leite, 2002). Esses são alguns motivos dos esforços mobilizados para qualificar o campo do lazer, em suas relações com os Estudos Culturais.

Sendo elemento cultural presente no cotidiano das pessoas, o lazer é prática política, econômica, humana e social. Mobiliza a cultura material e simbólica dos sujeitos e as transformações e acontecimentos da sociedade. As práticas de lazer tornam-se profícuas para entender as identidades culturais contemporâneas.

A produção científica do lazer tem-se aproximado de grupos marginalizados, culturas juvenis violentas, políticas de segurança pública e profissionais de educação física que intervém em comunidades pobres, com poucos recursos materiais e dificuldades de promoção da cidadania (Santos, 2013b).

Para Brasileiro (2013, p. 107), encaminhar novos saberes e outras perspectivas para os estudos do lazer sugere o entendimento das transformações socioculturais, pois vivemos "um tempo com novas configurações e realidades novas", demandando, a interpretação de "novas categorias e uma linguagem também nova, para as quais, ainda não possuímos um arcabouço teórico bem desenvolvido”.

Dessa forma, os Estudos Culturais vêm ampliar o olhar sobre o lazer, visto que, visualizam a cultura como modo de vida e não um elemento de distinção social. Ao passo que foi buscando um esclarecimento das modificações e formas de resistências da cultura pós 60, que os Estudos Culturais, segundo Martins (2011), deslocaram inúmeras reflexões para entender os estilos de vida das sub-culturas e grupos sociais.

A despeito dos Estudos Culturais discutirem um campo social marcado por lutas, negociações, conflitos, consensos e interesses políticos, no Brasil, eles ainda aparecem com timidez em algumas áreas. Só, aproximadamente nos últimos 20 anos ganham notoriedade nos estudos de Educação Física e Lazer. O que fica demarcado que os 
Estudos Culturais circunscrevem-se, principalmente em nosso meio, nas ciências sociais e humanas (História, Sociologia, Comunicação, Antropologia, Educação e Psicologia).

Parto das arquiteturas e cartografias das identidades culturais como aspectos marcantes da vida cotidiana. Também dos sujeitos, suas experiências, contextos, práticas, tempos e espaços sociais que se apresentam como desafios para formação e atuação do profissional em lazer.

Estudar a cultura no lazer exige apreender as práticas cotidianas, adotar posturas metodológicas e métodos resignificados de pesquisa. Nesse sentido, abrem-se possibilidades de avançar com os estudos da área. E se ancorarmos nos Estudos Culturais, as perspectivas de compreensão da estrutura cultural de lazer se ampliam.

Logo, apropriar do arcabouço teórico de um dos pais fundadores dos Estudos Culturais torna-se desafio como estudioso do lazer, e de certa forma, um novo procedimento de reconstrução dos saberes profissionais.

A seguir, apresento as concepções de sujeito e as transformações nas noções de identidade cultural. Posteriormente, articulo lazer com currículos pós-modernos para desafiar a formação e a atuação profissional na área.

\section{O sujeito iluminista}

Criadas para explicar nossa existência no mundo e constituir consciências, as concepções de sujeito funcionam para estruturar o eu significante na formação da identidade e construir interações dos indivíduos com a sociedade.

Segundo Hall (1997), concebendo os indivíduos como seres dotados de capacidade racional e fixação na realidade, o sujeito iluminista criou o ideal de que somos capazes de elaborar um interior e externalizá-lo como saber pronto.

Neste caso, o indivíduo é definido biologicamente e não sofre interferências do mundo social. E do nascimento até a morte é entendido como resultado do individualismo, onde o meio externo ao sujeito é neutro, sem história e dinamicidade.

Tal perspectiva, gestada no seio da filosofia ocidental moderna, foi influenciada pelo pensamento do filósofo, matemático e francês, René Descartes (1596-1650). De acordo com Hall (1998), Descartes pensou o sujeito portando um centro racional e cuja identidade é formada pelo eu interno, constituído por substância espacial, fruto do pensamento lógico-matemático. 
Sabe-se que essa concepção de sujeito está presente em diversos projetos e propostas de formação profissional em lazer, entretanto, torna-se necessário a superação dessa abordagem, identificando trabalhos teóricos e práticos que possibilitem soluções a esse respeito.

O estudo de Isayama (2010), por exemplo, identifica que estudar a ação profissional em lazer numa visão restrita da realidade é necessário para ampliar as perspectivas de formação na área. Segundo o autor, compreender o processo de construção de significados culturais, pedagógicos e sociais em lazer contribui na superação de propostas fundadas no conhecimento dado.

Contudo, significados não podem ser compreendidos mecanicamente, visto que, do contrário, iremos reforçar posturas dadas de formação de sujeitos. O interessante é transformar as ações práticas e teóricas no âmbito dos processos educativos e de lazer.

Espero que as ações profissionais em lazer sejam estudadas com o objetivo de resolver os problemas sociais ocultos nas propostas de intervenção, e que as desigualdades sociais e econômicas dos contextos, bem como conteúdos do lazer, metodologias, intervenções e currículos sejam problematizados.

Apesar disso, cabe destacar que, as teorias de análise ensinadas nos processos profissionais de formação precisam possibilitar o conhecimento das realidades, o aprimoramento das técnicas recreativas, esportivas, culturais e os saberes de jogos populares praticados por grupos específicos. Isso irá, grosso modo, qualificar o universo de saberes sobre as competências requeridas para intervir com práticas de lazer.

O profissional atento à construção de significados culturais, pedagógicos e sociais na atuação precisa perceber o valor da teoria na ação e o limite da própria intervenção. Com isso, entendo a teoria como uma possibilidade de transgressão da realidade, embora, persistam teorias que foram mal formuladas e não atendem aos contextos e sujeitos específicos. As realidades são tão complexas que a própria produção científica não dá conta de saber.

Devo dizer que questionar o caminho da pesquisa torna-se movimento de resistência contra a formação inicial vivenciada no passado e, atitude crítica frente às representações incorporadas no presente. Para mim não deixa de ser uma postura adequada no sentido de vislumbrar o futuro. 
$\mathrm{Na}$ atualidade, o que se vê, é que propagam visões restritas de lazer nos meios de comunicação de massa. Imagens de projetos sociais em propagandas muitas vezes ocultam as injustiças reais. Não sendo apenas ação da mídia, universidades públicas, artes e campo político apresentam concepções de lazer arraigadas em propostas seletivas e excludentes.

No Brasil, candidatos à reitoria de uma Universidade Federal colocaram como prioridade de sua gestão, na área de Artes, Cultura, Esportes e Convivência, a seguinte proposta: "revitalizar o Centro Esportivo Universitário (CEU) e viabilizar esse espaço para uso da comunidade universitária” e, "disponibilizar as dependências do Centro de Treinamento Esportivo (CTE) para o desenvolvimento de atividades de lazer de interesse da comunidade universitária” (Emediato e Tavares, 2013, p.21).

Nesse caso, já se seleciona a quem devem interessar as atividades de lazer e os espaços usados para tais fins. Universitários e comunidade acadêmica são públicos privilegiados. Por isso, os candidatos à reitoria negligenciaram que a Universidade deve proporcionar interação de ensino, pesquisa e extensão em favor das comunidades, ou que a Universidade é espaço público de interesse coletivo e cujo papel é de produzir conhecimentos de qualidade com acesso para toda população.

No campo da arte, Prysthon (2011, p.167) afirma que o lazer é visto como entretenimento e não componente de seriedade. Para ele, "o entretenimento vai assim se agregando à noção de lazer e incorporando em alguma medida a carga negativa que ela implica (ser o avesso do trabalho, o lugar da irresponsabilidade, o tempo ocioso, o contrário da obrigação)”.

As pessoas veem o lazer como reposição da força de trabalho e válvula de escape, outrora minimizando os conflitos sociais comunitários. O campo político também o observa como um dos componentes do direito social e bom número de projetos sociais faz seu uso para obtenção de votos nas campanhas eleitorais.

No setor mercadológico, o lazer aparece como elemento lucrativo da indústria do entretenimento, tanto na prestação de serviços quanto na comercialização de produtos. Aqui, despontam-se as diversões e divertimentos no tempo livre de crianças, jovens, adultos e idosos.

Noto nessas visões de lazer a noção do pronto e acabado, assim como sua transição em diferentes tempos e espaços sociais. O lazer é alvo dessa variedade de atores, por ser uma prática política, humana, econômica, cultural e social. O mesmo reúne 
consumidores, empresários, educadores, trabalhadores, alunos, políticos, atletas, cidadãos, dentre outros.

$\mathrm{Na}$ produção científica do lazer, é preciso contrapor lógicas de pesquisa e práticas docentes dadas, enfrentando-as com incertezas (Marques, 2012). Esse autor afirma que, ao trabalhar com certezas, pesquisadores e docentes do lazer possuem discursos democráticos, participativos e que realizam métodos dialéticos nas pesquisas e relações de ensino-aprendizagem. No entanto, práticas discursivas nessa área têm-se utilizado de estratégias que minimizam o aparecimento de questões levantadas pelos estudantes.

Ao focar as ações e discursos docentes, incoerências entre teoria e prática docente poderão aparecer, e assim, intervenções lineares e mecânicas na educação e no lazer abrem possibilidades de investigação da neutralidade. Tanto educação quanto lazer não são campos ou fenômenos isolados dos discursos políticos, econômicos e acadêmicos.

O que Marques (2012) nos coloca é que a pesquisa científica permite levantar dúvidas, incertezas, conflitos e colocações de perguntas, portanto, espaço para o questionamento de receitas, certezas e estratégias fabricadas para uso ou consumo, ações comumente encontradas no lazer e na educação.

Assim, as práticas teóricas formuladas em programas curriculares de formação em lazer precisam ser estudadas, levantando as ações aproximadas do concreto da realidade, visto que, do contrário, teremos o dilema do discurso $\mathrm{X}$ e a prática $\mathrm{Y}$, onde a teoria pode ser dialética, mas a prática iluminista.

Considero que se a formação do profissional em lazer for dialogada com respeito aos interesses culturais e políticos, voltando-se para capacitar ações coletivas com comunidades, aquela atenderá aos anseios de democratização pública do lazer.

Todavia, conhecer o funcionamento dessa concepção de sujeito não é garantia que as práticas sobre o uso do tempo livre e a ocupação da população no lazer serão compreendidas. A ideia aqui é problematizar essa abordagem e ver até onde as experiências práticas de lazer podem ser iluminadas noutras concepções.

\section{O sujeito sociológico}

Este sujeito é sistematizado a partir da interação ser humano e mundo social vivido, o que corrobora para internalização de relações coletivas e mediadas por práticas simbólicas. Com isso, as subjetividades constroem-se na cultura e na identidade idealizada, uma vez que aquela estabiliza o indivíduo e esta o prevê articulado na estrutura. 
Nas palavras de Hall (1998), os interesses subjetivos alinham-se às condições objetivas da realidade. E foram as ciências sociais as responsáveis por criar noções de que o sujeito é coerente e previsível, e a identidade cultural construída pelas nações e regiões nacionais unificadas. No entanto, "a identidade totalmente segura, completa, unificada e coerente é uma fantasia" (Hall, 1997, p. 10), uma imaginação elaborada. A unificação cultural é uma fantasia construída e, com isso, a identidade, a nação e a cultura nacional são comunidades imaginadas e elaboradas pelos discursos. Processos de formação aliam-se projetos de socialização e sociedade. Para Hall, a teoria social (Sociologia):

Localizou o indivíduo em processos grupais e normas coletivas que, argumentava, sustentam qualquer contrato entre sujeitos individuais. Ela desenvolveu, portanto, uma explicação alternativa de como os indivíduos são formados subjetivamente, através de suas associações e participações em relações sociais mais amplas; e, inversamente, de como processos e estruturas são sustentados pelos papéis que os indivíduos neles desempenham (Hall, 1997, pp. 31-32).

Entende-se a teoria social no processo de mediação das instituições coletivas de representação cultural e significação simbólica, ao passo que as especialidades profissionais adotam métodos de isolamento dos indivíduos, controlando seus comportamentos com modelos de formação técnica (Hall, 2006).

Postulando uma relação social estável e estruturada entre subjetividade, identidade e sociedade, a sociologia auxiliou na organização das contradições humanas. Também contribuiu com a política no sentido de administrar a oferta de direitos e serviços que gerenciam necessidades humanas, ou, outrora, para ampliar demandas do mercado e regular os interesses das políticas dos Estados.

Nessa ótica, "as teorias liberais clássicas de governo baseadas em direitos individuais e consenso viram-se obrigadas a chegar a um acordo com as estruturas do estado nacional e as grandes massas que constituem uma democracia moderna" (Hall, 1997, p. 29).

Encontra-se aqui um ponto de convergência para se pensar a relação lazer, mercado e Estado. Conforme destaca Lopes (2012), as demandas de grupos organizados do mercado e do Estado ampliam ou restringem os serviços e direitos sociais, assim como as atividades e políticas de lazer. O setor público oferece de modo fragilizado e precário às práticas, espaços e manifestações culturais nesse setor. Desta forma: 
As ações de lazer nos espaços públicos têm muitas vezes, reproduzido práticas globalizadas, sem respeitar e envolver as identidades culturais locais; partem de organizações sociais e institucionais com interesses diversos e são difundidas sem uma intervenção pedagógica crítica, dificultando ainda mais o estabelecimento da especificidade e das possibilidades educacionais (Lopes, 2012, p. 17).

Considera-se que as ações de lazer nos espaços públicos precisam estabelecer diálogos locais, respeito à especificidade de grupos e projetos educativos. Pesquisar ações nessa área exige reconhecimento da diversidade dos grupos sociais e qualificação constante da intervenção profissional (Lopes, 2012).

Entretanto, não é apenas dialogando e respeitando, ou implantando ações educativas que se avançará com as propostas públicas de lazer. Embora esses critérios sejam importantes, os profissionais da área têm uma tarefa crucial, a de identificar quais políticas e práticas estão ancoradas no sujeito sociológico, a fim de minimizar os variados currículos de conformação e adaptação do humano.

Freire (2005) compreende a adaptação como um movimento inferior do ser humano, já que no processo adaptativo ocorre a submissão dos indivíduos às condições hierárquicas da sociedade. Os sujeitos necessitam mobilizar movimentos de inserção no contexto social, tornando-se ativos na busca pelo poder e na superação das condições vigentes.

Nesse movimento de inserção ativa no contexto de trabalho, os profissionais de lazer com suas práticas poderão ampliar a intervenção e desenvolver questionamentos como, por que modelos de Estado de Bem Estar Social ou políticas sociais são oferecidas tendo o lazer como área importante? De que maneira eles/elas veem o lazer e por que veem dessa forma e não de outra?

No Brasil, as políticas sociais têm operado com o lazer em programas e projetos de promoção da cidadania, assim como na diminuição da vulnerabilidade social. Políticas de esporte, educação e segurança pública utilizam-se do lazer como um campo de interlocução (Santos, 2013b).

A partir da Constituição Nacional de 1988, o lazer passou a figurar como um dos direitos sociais e tornou objeto de diferentes ações políticas. No entanto, práticas recreativas e esportivas já faziam parte do cenário brasileiro, ainda no começo do século XX. Apesar de que aqui não se têm afirmações concretas de que houve um Estado de Bem Estar Social como dos países da Europa. 
Para Delgado e Porto (2007, p. 20) o Estado de Bem Estar Social "é certamente a mais completa, abrangente e profunda síntese dos grandes avanços experimentados pela história social, política e econômica nos últimos trezentos anos”. Ainda segundo os autores, "somente um Estado de Bem Estar Social, adequado às peculiaridades latinoamericanas e brasileiras, em particular, será capaz de tomar medidas eficazes assecuratórias de um significativo crescimento econômico com a simultânea construção de justiça social” (p.29).

Mas por que será que mesmo em países desenvolvidos e com históricos de Bem Estar Social coeso, existam ainda taxas nada desprezíveis de desigualdades sociais e pobreza. Fora isso, se focarmos os países pobres, a discrepância entre desenvolvimento social, político e econômico pode não demonstrar grandes avanços de justiça social, embora proclamadas pelas políticas de Bem Estar.

$\mathrm{Na}$ América Latina, dados econômicos e sociais não confirmam que os serviços proporcionados pelas políticas sociais são tão avançados como dos países ricos. No Brasil, políticas sociais devem ser estudadas e analisadas nos currículos de formação profissional em lazer, no intuito de aprimorar saberes, práticas e produções científicas.

Encaminho a proposta de que a formação profissional em lazer aborde estudos comparativos de sistemas de proteção social e Estado de Bem Estar Social de países ricos e pobres, bem como a retração e a expansão de ambos na sociedade contemporânea, isto é, pensar as implicações disto nos campos de formação profissional que atuam com lazer.

"Nesse contexto não se podem desconsiderar a precarização do trabalho e a perda da proteção social, fatores que interferem diretamente na subjetividade do profissional" (Isayama, 2010, p. 18).

O Estado de Bem Estar Social é um mecanismo funcional e de continuidade do sistema de produção e reprodução capitalista. Ele acompanha o desenvolvimento da produção econômica, a retração e expansão do sistema de proteção aos indivíduos, embora, com regulação e desregulação do trabalho junto aos sistemas econômico-sociais (Delgado e Porto, 2007).

A formação do profissional em lazer não está isenta dos sistemas de estruturação das políticas sociais na área, e estas se voltam para a formação de consensos, regulações e controles, mas também de discursos e práticas políticas de interatividade humana com a sociedade. Logo, políticas e identidades são sistemas sociais que precisam ser 
problematizadas, elas são categorias de análise ou pressupostos teóricos para entendermos o cotidiano do lazer.

\section{O sujeito pós-moderno}

Apesar das concepções iluminista e sociológica verem-se desestabilizadas pela concepção pós-moderna, é imprescindível entender quais interesses essa última atende. Essas concepções são criadas de acordo com as mudanças sociais e culturais de cada época e acompanham as modificações da mentalidade intelectual em cada período, situada no contexto histórico e político.

Hall (2006) considera o pós-moderno uma nova forma de pensar humanidade e social. São os processos de reestruturação da sociedade capitalista e a própria noção de ser humano que estão mudando, por isso, o pós-moderno é aquele que está entrando em colapso, devido às desestruturações do nosso tempo. A identidade agora é provisória, móvel, múltipla, contraditória e diversificada.

No mundo globalizado e pós-moderno, teorias buscam superar as concepções iluminista e sociológica, bem como os sujeitos e identidades nelas imbricadas. Sabe-se que elas criaram fundamentos teóricos, práticos e lógicos, mas não diminuíram os conflitos entre desejos e interesses humanos (Hall, 1998).

Caberia então deslocar a fixação e centralidade dos sujeitos na contemporaneidade. Seguindo as pistas de Hall (1997, p. 09) “o que é por vezes descrito como nosso mundo pós-moderno, também somos pós no que diz respeito a qualquer concepção fixa ou essencialista de identidade”. De tal maneira, somos interpelados a romper com visões simplificadas da realidade.

Isso exige teorizações em abordagens materialistas, históricas e dialéticas, cabendo revisitar trabalhos de Marx (1982) sobre modos de produção e exploração da força de trabalho e Althusser (1967, 1974) acerca da ideologia; Freud (1996) e Lacan (1996) sobre a descoberta do inconsciente e dos processos psíquicos; Ferdinand de Saussure (2006) e Jacques Derrida (2002) sobre estrutura e filosofia da linguagem; da mesma forma, Foucault $(2004,2005)$ acerca da genealogia do sujeito moderno e poder disciplinar; outrora, estudos feministas, negros, de movimentos sociais e políticas identitárias do início dos anos 60 do século passado (apud Hall, 2006).

O exame rigoroso desses estudos possibilita o descentramento do sujeito racional e previsível, oferecendo outras leituras da identidade. Conforme salienta Hall (1997, p. 26), esse conjunto de autores permite afirmar que: "as identidades modernas estão 
sendo fragmentadas... o que aconteceu à concepção do sujeito moderno na alta modernidade não foi simplesmente seu estranhamento, mas seu deslocamento”.

Da mesma forma, citado por Hall (1998) a ideia de descontinuidade de Giddens (1990), o pensamento de ruptura e fragmentação de David Harvey (1989), e o conceito de deslocamento e descentração de Ernest Laclau (1990) permitem a sistematização aberta da identidade.

Acredito no diálogo entre esses autores e a teoria do lazer, primeiro, por este campo requisitar novas descobertas e interpretações que contribuam com a temática da identidade. Segundo, por ser a identidade um elemento essencial na compreensão da cultura. Terceiro, porque boa parte dos estudos do lazer entendem a cultura como constituinte do seu conceito e da conformação de teorias na área, ressoando assim, na formação de identidades profissionais em lazer.

Com base nisso, esse profissional poderá descobrir concepções e entender fenômenos que interferem na construção da cultura e da identidade, já que sua ação afeta propostas e ao mesmo tempo, provoca avanços e limites teóricos e práticos.

Descobrir conhecimentos e compreender saberes passa pela ideia de que, "nada seria mais compreensivo do que indagarmos sobre nossa própria existência, levantando questões que certamente nos levariam a uma maior percepção de nós mesmos e do meio que nos envolve" (Pereira et al.2012, p. 9).

O compromisso dos estudos do lazer passa pelo pensar crítico, mas a ele não se deve prender. É coerente formar profissionais éticos para desmobilizar a colonização do saber e o poder eurocêntrico em nosso meio. Assim como, valorizar saberes dos povos da América Latina, equilibrando a importação de conhecimentos de outras partes do globo, embora estes últimos pesem sobre nossa realidade social e histórica (Gomes, 2011).

Marques (2012) acredita na interdisciplinaridade para os estudos do lazer e no cruzamento das fronteiras de diferentes campos disciplinares, amarrando a complexidade do pensamento. $\mathrm{O}$ autor indaga o anti-isolacionismo das disciplinas acadêmicas e debate modos de se produzir conhecimento científico sobre lazer.

Por mais que os processos sociais transformam o ser humano e o meio ambiente, no mundo pós-moderno, o que prevalece é o sentimento de dúvida, instabilidade subjetiva e formação "hibridizada" das identidades. O sujeito atual vive com ações instáveis, incorpora fragmentações, mas também modifica estrutura e instituções do cotidiano. 
Por isso, torna-se relevante descentrar lugares, conhecimentos e sujeitos da experiência com práticas de lazer. Portanto, descentrar é uma ação de competência desse profissional, sobretudo no campo da pesquisa, formação e atuação.

A pós-modernidade acentua debates de tempo e espaço, sujeitos e identidades na cultura, e ambas temáticas são de interesse do profissional do lazer. Ademais, o desenvolvimento humano e a transformação social compartilham dessas demandas, frutos dos avanços comunicacionais e informacionais da sociedade do conhecimento.

Vive-se em um tempo e espaço de novas competências técnicas, políticas, dinâmicas e tecnológicas para o uso dos profissionais. Por conseguinte, torna-se parte do processo de trabalho saber empreender, questionar, refletir, selecionar e mobilizar técnicas e conhecimentos tecnológicos.

\section{Da Formação profissional em lazer: O enfoque do currículo}

Lazer é um campo de intervenções multiprofissional, requer abordagens distintas nos estudos da realidade e uma formação profissional ancorada em currículos interdisciplinares. Isayama (2010) acredita que as ações em lazer devem priorizar experiências culturais com grupos e sujeitos dos mais variados.

De acordo com Marques (2012), o lazer permite exercício dialógico, complementar e antagônico entre as disciplinas e ciências, e pode favorecer relações e cruzamentos de fronteiras com outros campos de investigação.

A interdisciplinaridade, ao caminhar na contramão do isolamento disciplinar e social, se difere do engessamento das ciências. Atualmente, enquanto as pessoas se afastam do convívio social, os profissionais se isolam em setores específicos de atuação. É justamente nesse ponto que a interdisciplinaridade busca entender os problemas sociais, para superar a violência nas cidades (Marques, 2012).

Todavia, atitudes de enfrentamento ao isolamento do pensamento nas ciências e nos campos profissionais demandam posturas ativas e dialogadas. Nesse sentido, superar a violência passa pela compreensão de aspectos profundos de sua emergência e do desenvolvimento dos indivíduos (Santos, 2013a).

Solucionar problemas humanos, naturais, sociais e tecnológicos exige rompermos com violências ameaçadoras da vida. E isso é o mínimo que se espera do compromisso das sociedades democráticas e socialmente saudáveis. 
Gomes (2011) afirma que é preciso encontrar "alternativas para enfrentar situações complexas, como as desigualdades sociais, os conflitos armados, a marginalização, a destituição de direitos sociais, a precarização do trabalho e as distintas formas de violência que marcam profundamente toda a região latino-americana, entre muitas outras" (p. 15).

A autora considera fundamental identificar de onde vêm os conhecimentos, práticas e teorias que fundamentam as questões sobre o lazer. Indica que a crítica na pesquisa possibilita entender de onde os conhecimentos foram produzidos e quais interesses de mundo defendem.

Por isso, formar profissionais em lazer demanda a construção de currículos acadêmicos, mas também cursos de qualificação oferecidos pelo mercado de trabalho, com iniciativas políticas e públicas. Acredito na construção e apropriação de saberes em espaços que apresentam conflitos e geram violências, pois nesses locais profissionais do lazer atuam com perspectivas para o desenvolvimento da pesquisa e da intervenção mediada (Santos, 2013b).

Se por um lado, formar profissionais exige pensar em propostas universitárias, por outro, requer a busca por espaços alternativos de qualificação e que ofereçam excelência ao conjunto diversificado de atores sociais, incluindo áreas e regiões que concentram elevados índices de homicídios, pobreza e conflitos entre pessoas (Santos, 2013b).

Os contextos pós-modernos são marcados por violências e carecem de novas práticas, serviços e equipamentos de lazer. Além disso, profissionais qualificados e que abordem conteúdos culturais nas políticas sociais em comunidades.

A interdisciplinaridade no âmbito acadêmico e profissional pode contribuir para a reconstrução e mobilização de saberes nas relações humanas, equilibrando desigualdades sociais entre pessoas e, minimizando violências.

Segundo Melo (2010), o profissional do lazer deve transpor os espaços e projetos tradicionalmente instituídos, isto é, atualizar no que diz respeito às técnicas de atuação, às manifestações e linguagens culturais, aos horizontes e dimensões formativas com diferentes linguagens, saberes e práticas.

Trato do lazer como cultura na perspectiva dos Estudos Culturais, o que demanda saberes interdisciplinares e conhecimentos dos modos de vida. Assim, a cultura é elemento central presente nas identidades dos sujeitos e nas ações de lazer. 
Portanto, entendo a cultura como lugar crítico e de relações de poder potencialmente incertas, presente nas práticas de lazer e serviços mobilizados por profissionais da área. Penso em ações culturais e currículos de lazer construídos nas relações de poder e na mobilização de saberes cotidianos (Santos, 2013b).

As práticas de lazer precisam superar visões dadas ou estáveis em projetos que imperam na área. Sendo um campo incerto e movediço, o lazer, se ancorado nos estudos da cultura, potencializa a área da formação e atuação profissional nas realidades. Embora, seja necessário assumir conflitos políticos, culturais e comunitários, abordando processos de atuação coletiva e compartilhamento da produção cultural e profissional.

Apesar de currículos profissionais em lazer serem construídos em lógicas das mais variadas, agregando concepções de sujeitos e de identidades, deve "haver alterações significativas a este nível, sendo necessárias mudanças de posturas e atitudes, reformulações de currículos, envolvimento e empenhamento por parte dos professores" (Pereira et al., 2012, p. 18).

Tão importante quanto construir currículos são as ações de resistir neutralidades nos mesmos, assim como resistir a passividade de alunos e professores na prática educativa e pedagógica. Sabe-se que a pós-modernidade anseia por currículos que desenvolvam formações com respeito à diversidade de etnias, gêneros e faixas etárias. Aliás, currículos que abordem culturas no plural e noutras lógicas de governar condutas.

Para Paraíso (2010) as práticas culturais e discursivas imprimem marcas ao currículo do lazer, e reforçam sistemas de produção e conteúdos formados por artefatos culturais. Estes são processos industriais de divulgação em massa e, em sua maioria, usados para entreter, divertir, formar, educar, moldar e transformar relações coletivas. O lazer está imerso em máquinas de ensinar, discursos, textos culturais, artefatos produtores de sujeitos, poderes, currículos e ações de governos.

Alguns programas educativos propõem conexões de lazer e currículos pela cultura, e também ensinam modos de conduzir comportamentos diante das ações profissionais nos contextos de criminalidade e violência entre jovens. (Santos e Isayama, 2014).

Trata-se de ver "os currículos e todas as práticas de lazer como artefatos culturais divulgadores e produtores de cultura... como uma prática discursiva... sempre associadas às relações de poder de diferentes tipos, presentes em todas as relações sociais" (Paraíso, 2010, p. 39). 
Como analista cultural do currículo, o profissional do lazer tem a função de analisar textos culturais, linguagens e discursos. "O currículo de formação em lazer necessita contemplar ferramentas que instrumentalizem" (Paraíso, 2010, p.44), acrescentando a leitura crítica dos artefatos culturais como currículos.

É papel do profissional do lazer racionalizar, instrumentalizar, oferecer ferramentas e delimitar caminhos de formação para o campo. Além disso, buscar linguagens, palavras, teorias e práticas com a cultura em constante devir. Como diriam Pereira et al. (2011, p. 9), de que "é um equivoco desprezar a cultura passada no presente e ignorar, no futuro, sua forma dinâmica e inacabada de ser”.

Os currículos de lazer incorporam significados e sentidos presentes nas identidades humanas e, embora sejam explicados por processos racionais significativos, não se encerram em si mesmos ou em conteúdos curriculares fechados, pois:

Tudo o que dizemos possui um antes e um depois, uma margem, na qual outros podem escrever. O significado é inerentemente instável: ele busca um fechamento (identidade), mas é constantemente rompido (pela diferença). Ele está constantemente fugindo de nós. Há sempre significados suplementares sobre os quais não temos qualquer controle, que surgirão e subverterão nossas tentativas de criar palavras fixas e estáveis (Hall,1997, pp. 44-46).

Essas idéias desmobilizam fechamentos e abordam outras dimensões de currículos, alternativas que trabalham no materialismo e em mapas contemporâneos de organização social.

Entendo o currículo mediado não apenas pelo professor, mas por pessoas que formam caminhos didáticos, pedagógicos e metodológicos com práticas de lazer, seja na escola ou na rua, no esporte, na política e nos costumes cotidianos, bem como na economia, ciências e tecnologias. A intervenção profissional em lazer passa pela dialética das profissões, fundando saberes concretos e abstratos, materiais e imateriais ao mesmo tempo.

No âmbito da cultura, ao produzir e ser produto dos significados que o cercam, os currículos são explicados e reconhecidos (Oliveira et al., 2007). É reconciliando a possibilidade de currículos como planejamentos abertos e imprevisíveis que, observa-se cidadãos e consumidores nas práticas de entretenimento, diversão, educação e lazer.

O currículo quando mediado é capaz de iluminar o oculto e, simultaneamente integrador do humano no ato de conhecer. O currículo do lazer, ao proporcionar 
reflexões sobre nossa época, incorpora práticas sociais e desafios do tempo e espaço das culturas.

A mediação em lazer é vista aqui como movimento curricular, com conteúdo, método, metodologia e lógica de avaliação da ação. Também compartilha visão, profissão, processo de ensino, contexto, tempo e identidade. O currículo mediado em lazer busca a ação de ensinar nos espaços e tempos que se modificam transitoriamente.

Devo dizer que o enfoque do currículo mediado é, por um lado, confrontador das identidades culturais e seus comportamentos contemporâneos e, por outro, perpassado pelos artefatos da globalização e das tecnologias da informação e comunicação.

No contexto pós-moderno, são muitos os currículos e dispositivos móveis que constituem identidades e sujeitos. Os currículos são novos sentimentos e desejos linkados por janelas e quadros de vidro. Eles são fronteiras e territórios presenciais, mas também espaços reais substituídos por tempos de representação virtual, e cuja temporalidade é mediada por espelhos e dispositivos de comunicação nas linguagens contemporâneas.

Os currículos vêm sendo formados por identidades do e no lazer e, portanto, são objetos que precisam ser questionados e compreendidos, mediados na sua interface com a formação e atuação profissional em lazer.

\section{Considerações finais}

Neste estudo, busquei ampliar as contribuições teóricas de Stuart Hall e pensar a formação profissional em lazer. Durante a revisão de literatura pesquisei as identidades culturais e as concepções de sujeito iluminista, sociológico e pós-moderno. Estes dados reúnem diálogos com os Estudos do Lazer, currículo e Estudos Culturais.

Os Estudos Culturais oferecem perspectivas para pensar os currículos do lazer impressos nos sujeitos, nos modos de andar, sentir, pensar e ser. Desta maneira, toda forma humana de ação compreende currículos impressos com características identitárias.

Nessa direção, instituições e estruturas sociais são responsáveis por construírem currículos que fornecem legados identitários na história. Currículos são objetos interdependentes de sujeitos, processos históricos, estruturas sociais e pensamentos políticos. 
As concepções de sujeito iluminista, sociológico e pós-moderno são extremamente atuais como teorias de análise. As mesmas são ferramentas analíticas para os profissionais do lazer, contribuem para identificar projetos de sujeitos, mapas contemporâneos das políticas de direito social e serviços de lazer, ambos acessados pelos cidadãos. O conhecimento destas teorias de análise fornece repertórios teóricos, metodológicos e práticos.

No mundo pós-moderno, lazer e identidades estão sendo movidos nos currículos escolares e não escolares, nas ações profissionais, nos programas de promoção da cidadania, sejam eles privados, públicos ou do terceiro setor. A veiculação de identidades ocorre nos mais diferentes espaços, eventos políticos, midiáticos, acadêmicos e práticas que adotam fluxos interculturais de saberes sobre lazer.

A formação profissional em lazer precisa extrapolar os horizontes de investigação. Deve-se inserir no contexto da atuação para perceber os currículos contemporâneos. Analisar programas de lazer na graduação e pós-graduação com estratégias que passam pelo discurso. Aliás, programas de lazer que fazem parte das agendas de pesquisas, atividades políticas e ações profissionais.

Formar para atuação com novas concepções de sujeitos é uma forma de mobilizar saberes no plano da cultura. Além disso, fabricar currículos de lazer voltados para as transformações sociais e democráticas.

Assumo as divergências da participação em sociedade, sobretudo num quadro de que "dentro de nós coexistem identidades contraditórias, pressionando em direções diversas, de modo que nossas identificações estão sendo continuamente mudadas" (Hall, 1998, p. 10).

Identidades culturais e currículos se encaixam na formação profissional em lazer e nas intervenções cotidianas. Por isso, atuo com a perspectiva de currículos mediados no lazer, o que não significa se fechar aos modelos de identidades e concepções de sujeito, visto que, num tempo em que as teorias funcionam como intervenção e o lazer se destaca com ações práticas e teóricas, o que se move e nos move são os sentidos e significados da cultura.

\section{Referências bibliográficas}

Althusser, L. (1967). Análise Crítica da Teoria Marxista. Rio de Janeiro: Zahar. . (1974). Aparelhos Ideológicos do Estado. Lisboa: Presença. 
Brasileiro, D. (2013). O lazer e as transformações socioculturais contemporâneas. Revista Lusófana de Estudos Culturais, 1 (2). 91-109. Recuperado em 15 de fevereiro, 2014, http://estudosculturais.com/revistalusofona/index.php/rlec/article/view/35/51

Deleuze, G. (1992). Conversações: 1972-1990. Rio de Janeiro: Trinta e Quatro.

Delgado, M. G.; Porto, L. V. (2007). O Estado de Bem Estar Social no capitalismo contemporâneo. In: Delgado, M. G., \& Porto, L. V. (Org.). O Estado de Bem Estar Social no Século XXI (Cap.1, pp. 19-30). São Paulo: LTR.

Derrida, J. (2002). A Escritura e a Diferença. ( $3^{\text {a }}$ ed.). São Paulo: Perspectiva.

Emediato, W; Tavares, R. H. (2013) Chapa 1: Candidatos a Reitoria da Universidade Federal de Minas Gerais. Recuperado em 20 de julho, 2013, de https://www.ufmg.br/eleicoes2013/wander-rosilene/

Isayama, H. F. (2010). Formação Profissional no Âmbito do Lazer: Desafios e Perspectivas. In: Isayama, H. F. (Org.). Lazer em Estudo: Currículo e Formação Profissional (Cap.1, pp. 09-25). Campinas: Papirus.

Foucault, M. (2004). A Arqueologia do Saber ( $7^{\mathrm{a}}$ ed.). Rio de Janeiro: Forense Universitária.

. (2005). Arqueologia das Ciências e História dos Sistemas de Pensamento. ( $2^{\mathrm{a}}$ ed.). Rio de Janeiro: Forense Universitária.

Freire, P. (2005). Pedagogia da Autonomia: Saberes necessários à prática educativa ( $31^{\mathrm{a}}$ ed.). São Paulo: Paz e Terra.

Freud, S. (1996). Edição Standard brasileira das obras psicológicas completas de Sigmund Freud: Os chistes e sua relação com o inconsciente. ( $8^{\mathrm{a}}$ ed.). Rio de Janeiro: Imago.

Giddens, A. (1990). The Consequences of Modernity. Cambridge: Polity Press.

Giroux, H. (1987). Escola Crítica e Política Cultural. São Paulo: Autores Associados.

Gomes, C. L. (2010). A contribuição da pesquisa para a formação profissional em lazer. In: Isayama, H. F. (Org.). Lazer em Estudo: Currículo e Formação Profissional (Cap.4, pp. 87-102). Campinas: Papirus.

Gomes. C. L. (2011). Estudos do Lazer e Geopolítica do Conhecimento. Revista Licere, 14 (3). 01-25. Recuperado em 22 de novembro, 2012, de http://www.anima.eefd.ufrj.br/licere/pdf/licereV14No3 ar1.pdf

Hall, S. (1997) Identidade cultural. São Paulo: Fundação Memorial da América Latina.

Hall, S. (1998). A questão da identidade cultural ( $2^{\text {a }}$ ed., A. B. M. Jacinto \& S. M. Frangella, Trad.). Campinas: UNICAMP/IFCH. (Obra original publicada em 1992). 
Hall, S. (2000). Quem precisa de identidade? ( $3^{\text {a }}$ ed., T. T. Silva, Trad.). In: Silva, T. T. (Org.). Identidade e Diferença: A perspectiva dos Estudos Culturais. Petrópolis: Vozes. (Obra original publicada em 1996).

Hall, S. (2006). Identidade Cultural na Pós-Modernidade ( $11^{\mathrm{a}}$ ed., T. T. Da Silva \& G. L. Louro, Trad.). Rio de Janeiro: DP\&A. (Obra original publicada em 1992).

Harvey, D. (1989). The Condition of Post-Modernity. Oxford: Oxford University Press.

Hoggart, Richard. (1973). Utilizações da Cultura: Aspectos da vida da classe trabalhadora. São Paulo.

Lacan, J. (1996). Escritos. (3 ${ }^{\text {a }}$ ed.). São Paulo: Perspectiva.

Laclau, E. (1990). New Reflections on the Resolution of our Time. Londres: Verso.

Leite, C. M. F. (2002). Currículo e o Multiculturalismo no Sistema Educativo Português. Lisboa: Fundação Calouste Gulbenkian.

Lopes, C. G. (2012). Os princípios políticos do BH cidadania: o olhar de profissionais da Secretaria Municipal Adjunta de Esportes. Dissertação de Mestrado, Universidade Federal de Minas Gerais, Minas Gerais, MG, Brasil.

Louro. G. L. (2004). Um corpo estranho: ensaios sobre sexualidade e teoria queer. Belo Horizonte: Autêntica.

Marques, W. E. U. (2012). Lazer, Pesquisa e Interdisciplinaridade: Algumas reflexões acerca do contexto atual das produções acadêmicas. Revista Licere, 15 (2). 01-16. $\begin{array}{lllll}\text { Recuperado em } & 25 & \text { novembro, }\end{array}$ http://www.anima.eefd.ufrj.br/licere/pdf/licereV15No2 ar4.pdf

Martins, M. L. (2011). Crise no castelo da cultura: das estrelas para as telas. São Paulo: Annablume.

Marx, K. (1982). O capital: Crítica da Economia Política. (8ª ed.). São Paulo: DIFEL.

Melo, V. A. (2010). A formação cultural do animador cultural: antigas reflexões, persistências, continuidades. In: Isayama, H. F. (Org.). Lazer em Estudo: Currículo e Formação Profissional (Cap. 6 pp. 127-142). Campinas: Papirus.

Oliveira, E. M., Almeida, J. L. V., \& Arnoni, M. E. B. (2007) Mediação Dialética na educação escolar: teoria e prática. São Paulo: Loyola.

Paraíso, M. A. (2010). Currículo e Formação Profissional em Lazer. In: Isayama, H. F. (Org.). Lazer em Estudo: Currículo e Formação Profissional (Cap. 2 pp. 27-58). Campinas: Papirus.

Pereira, A., Isayama, H. F., Silveira, L., \& Cunha, C. (2012). Educação Física, Lazer e Multiculturalismo: Sentidos e Desafios. Revista Licere 15 (3). 01-26. Recuperado em 20 de novembro, 2012, http://www.anima.eefd.ufrj.br/licere/pdf/licereV15No3 ar1.pdf

Prysthon, A. (2011). Richard Dyer: utopias da frivolidade. In: Junior, J. J.; Gomes, I. M. M. Comunicação e Estudos Culturais (Cap. 10 pp. 163-176). Salvador: EDUFBA. 
Santos, S. (2013a) Dialogando com Stuart Hall: Algumas contribuições para a formação profissional em Lazer. Anais do Congresso Internacional em Estudos Culturais "Ócio, Lazer e Tempo Livre nas Culturas Contemporâneas", Aveiro, Portugal, III.

Santos, S. (2013b). A intervenção no lazer na política de segurança pública: a construção de saberes dos oficineiros do Programa Fica Vivo!. Dissertação de Mestrado, Universidade Federal de Minas Gerais, Minas Gerais, MG, Brasil.

Santos, S., Isayama, H. F. (2014). O lazer na política de prevenção social à criminalidade de Minas Gerais: O programa Fica Vivo! Revista Brasileira Ciência e Movimento 22 (1). 58-69.

Sovik, L. (2011). Pensando com Stuart Hall. In: Junior, J. J.; Gomes, I. M. M. Comunicação e Estudos Culturais (Cap. 3 pp. 49-62). Salvador: EDUFBA.

Saussure, F. de. (2006). Curso de Linguística Geral. (2º ed.) São Paulo: Cultrix.

Thompson, E. P. (1998) Costumes em Comum. São Paulo: Companhia das Letras.

Williams, R. (1992). Cultura. Rio de Janeiro: Paz e Terra.

Samuel Santos é Licenciado em Educação Física, Especialista em Docência e Gestão do Ensino Superior, tem mestrado em Estudos do Lazer, sendo Docente do Curso de Licenciatura em Educação Física da Universidade Estadual de Minas Gerais. Também é professor municipal da Prefeitura de Belo Horizonte, Brasil e pesquisador do Laboratório de pesquisa sobre Formação e Atuação Profissional em Lazer (ORICOLÉ). samusantoso8@yahoo.com.br 